\title{
Search Engine
}

National Cancer Institute

\section{Source}

National Cancer Institute. Search Engine. NCI Thesaurus. Code C68817.

A computer program that retrieves documents or files or data from a database or from a computer network. 